\title{
History of Electronic Prescriptions in Sweden: From Time-Sharing Systems via Smartcards to EDI
}

\author{
Gunnar O. Klein \\ Department of Microbiology, Tumor and Cell Biology \\ Karolinska Institutet, Stockholm, Sweden \\ gunnar.kleinaki.se
}

\begin{abstract}
Managing prescriptions for medication, using ICT support, started in the 1970s with the computerization of the pharmacy branch offices where local systems registered handwritten prescriptions and to print labels. In 1984, the first online prescribing started with physicians connected to their local pharmacy system in a pilot test. Then in 1987, the first pilot test started with an off-line system in which PC-based prescriber support systems transferred data to patient-held smart cards that were taken to the pharmacy. In the 1990s, we had the first use of messaging using EDIFACT syntax for prescriptions. These had a relatively small volume until 2000, when an XML version of a European standard based on object-oriented modeling became popular and made electronic prescribing the normal practice, which meant important quality gains.
\end{abstract}

Keywords: Decision support, electronic prescriptions, Infocard, messaging, standards.

\section{Introduction}

Computer support for the process of managing medication prescriptions is an interesting example of the developments of what we now call eHealth ${ }^{1}$. There were a number of relatively early developments in this sector using computers, but the large-scale adoption of the new techniques has been slower than in many other sectors. However, the history of ICT use for prescriptions in Sweden offers several interesting aspects that touch upon technology as well as informatics and societal issues. Today, these techniques affect almost every citizen, since most people use prescription medication at one time or another.

Some of the medication issues addressed by ICT are:

- Decision support for the prescribing physicians improves the quality of medication selections, optimizes the possibility of efficacy, and minimizes the risk of adverse reactions. In Sweden alone, an estimated three thousand deaths occur yearly due to errors in medication.

\footnotetext{
${ }^{1}$ http://www.ehealthweek2010.org/ this year's EU ministerial and scientific conference.
} 
- Improved cost-efficiency for the pharmacies has occurred by changing almost illegible paper scripts to computerized support for retail, billing, and safety checks.

- Improved services provided to customers/patients.

\section{Background}

This paper is based on a literature study and the experience of the author who, in leadership positions, has had the privilege of not only observing, but also actively participating in the developments described herein.

During the period 1972-73, the author worked for Philips Bank Terminal Systems where an interesting and not very well-known computer was constructed based on developments from the Arenco Company bought by Philips. This was a minicomputer, with a set of special printers, displays and keyboards, also manufactured by the same company, to manage five working terminals at a bank branch office. The author designed the testing software for the factory and service personnel, including the design of a simple time-sharing operating system (OS). The computer had no general OS available at first. It had a core memory and sixteen instructions programmed, using punched cards at the beginning, with an assembly code that transferred to a machine code 20 kilometers away, once daily. Much of the debugging took place using a special hardwired unit with bit switches and lights, which allowed patching in the core memory. Apoteksbolaget (the National Corporation of Swedish Pharmacies) bought these printers for all the pharmacies in Sweden in the 1970s.

In 1987, the author had become a medical doctor with some limited experience of writing prescriptions, and $\mathrm{a} \mathrm{PD}$ in cancer research with many data management projects at Karolinska Institutet. He then founded the company, Infocard Nordiska $\mathrm{AB}$, in which a staff of ten worked to pioneer the development of applications for the new memory card technologies in Sweden. Firstly, laser optical cards from Canon were used that could hold some $500 \mathrm{kB}$ of data. The aim was to compile an entire medical record that the patient could hold. This technique had several problems, such as poor reliability and the expense of the equipment needed for reading/writing. Focus then switched to smartcards. Besides Bull, Infocard was the only significant company in Sweden with such expertise, and for some five years worked closely with Televerket (the National Telecommunications Administration) in several projects crowned by the system for GSM. The cards and the personalization systems for all the Nordic countries came from Infocard. Nevertheless, the heart of the author was with the medical applications and he led the development of the prescribing system described in this article.

During 1993-2000, the author worked for both the Swedish Institute for Health Services Development (Spri) and Karolinska Institutet where he started the Centre for Health Telematics in 1996. He was working both with European R\&D projects and standardization for health IT, first with health care cards, later information security, and object oriented information models and semantic interoperability. In addition, the author was the coordinator of the EU project, Trusted Health Information Systems, 
which developed the principles for the use of cryptographic services in health care using PKI and smart cards as electronic identity cards for use by the health professionals. In 1997, he became chair of all European standardization for health informatics, operating with EU mandates and financing. Then in 1998, he co-founded the corresponding ISO committee. During this period, Europe developed both a formal standard for electronic prescriptions and various important security standards. The patient card standardization became global and now it has an eight-part ISO standard that includes a part for electronic prescriptions.

Since 2000, the author has continued to work for health care standards and other issues in medical informatics. He was instrumental in the development of the Swedish e-prescription specification, which is a profile of the European standard expressed in XML. In 2007, his long-term work for electronic prescriptions was published as an ISO Technical report [1]. Since 2008, the author's main job is as primary care physician who makes daily use of the electronic prescription and various decision support systems.

\section{Pharmacy Computerization in Sweden - The Early Phase}

Between 1970 and 2009, the National Corporation of Swedish Pharmacies (Apoteksbolaget $\mathrm{AB}$ ) was the sole pharmacy retailer in Sweden. This unusual situation enabled it to invest in ICT developments much earlier than in the other Nordic countries and in Europe as a whole. During the 1970s, all the nine hundred branch offices received a minicomputer with custom-built software from the Swedish branch of Data General. Special dot matrix printers were custom-built to meet the size requirements of the labels for the patient's name and dosing instructions for the medication package. This computerization, first made to simplify the retail and safety checks, also led to the development of a national database for all prescriptions, at a very early stage, compared internationally. This has been very useful for many studies of medication use as well as finding side effects. The National Corporation of Swedish Pharmacies compiled it and then it transferred to the National Board of Health and Welfare for analysis.

There have been a number of generations of this system for the pharmacies. Different methods that also included the prescribing physicians were considered and tested. The first trial was in Bankeryd in the Småland region where the pharmacy and the primary care center were located in the same building. A module was slightly adapted from the one that the pharmacists use to enter paper prescription data. Some of the physicians who received terminals (the $80 \times 25$ line text ones used by minicomputers at the time) to the pharmacy computer, on which they could enter their prescriptions, used this. The physicians had access to a list of all the products with names and packages, but not much decision support.

\section{The Communication and Security Problems}

During the 1980s, the networks did not reach all the primary care centers in the country; dial-up connections using standard telephone lines were all that was available. 
The speed, 9,600 baud, could be enough to send an occasional prescription, but it was not enough to browse through databases for pharmaceutical information for the prescriber, for example. There were also serious security concerns regarding the need to protect the confidentiality of patients' health information and the authenticity of legally regulated documents such as prescriptions. These concerns meant that new solutions had to be found for the prescription communication.

This was one reason for our idea of using the new microprocessor cards (named Smartcards by Roy Bright) for prescriptions. Our new concept was not only a means of protecting the confidentiality during a one-time transfer from the prescriber to the pharmacy, it also included allowing the patient to carry a complete history of all current medication, often prescribed by different providers, to hospitals as well as outpatient clinics. A national database, which could have been an alternative solution, was, at the time, not considered feasible, due to data protection regulations.

The first commercially available smartcards were the BULL CP8 cards with 8 kbit=1 kbyte of storage. This was insufficient for the application, which would allow patients to take a complete medication history and other data, such as allergies, to medical facilities. However, Infocard became a distributor for Matsushita/Panasonic that introduced 2- and 8-kbyte smartcards in 1986. Most of the pilot tests used the 2kbyte smartcards, whose capacity, with our compact storage, was enough for fifteen current prescriptions and fifty old ones, as well as some other information.

\section{The Prescriber Support System}

The prescriber support system developed by Infocard in 1986-88 was innovative in several ways. It received considerable attention from the smartcard community and it enjoyed presentations at various conferences [2].

This rather advanced decision support system could be presented, with all the previously prescribed medicines, possible allergies and renal function, to the prescribing physician. In addition, it also included information on the products and their use, data that was derived from three sources:

- The Product database used by the pharmacies, updated each month on a diskette, contained the name of the product, its ingredients, strength, packages, and prices.

- The Pharmaceutical information, "Läkemedelsregistret," included about two pages of information on each product with Indications, Contraindications, Recommended Dose, Side effects, and several more items.

- The Problem-Oriented Drug Book, "Läkemedelsboken," a five hundred page volume with some twenty chapters for each major disease or problem category (i.e., Pain is not a disease but an important reason for medication). Named experts wrote this book that build on scientific references and various consensus guidelines, and they still publish it regularly. It not only provides advice on the major classes of drugs for illness such as depression, but it also provides guidance for diagnoses and alternative therapies that do not involve medicines. Previously only available in print, it is now also accessible as a PDF version on the web. Our team acquired the magnetic tape used for the 
typesetting machine at the printers and, because it was systematically organized with various control codes for chapter, subchapters, and so on, they were able to automatically create a very adequate database from this book for use in the local system,

The above-mentioned last part about guidance, based on the intended problem to be treated, was one of the unique features of the support system. Interestingly, now over twenty years later, none of the prescriber support systems has such a feature, partly because the source book does not appear to be a database [3]. Fig. 1 depicts the workflow using these three sources.

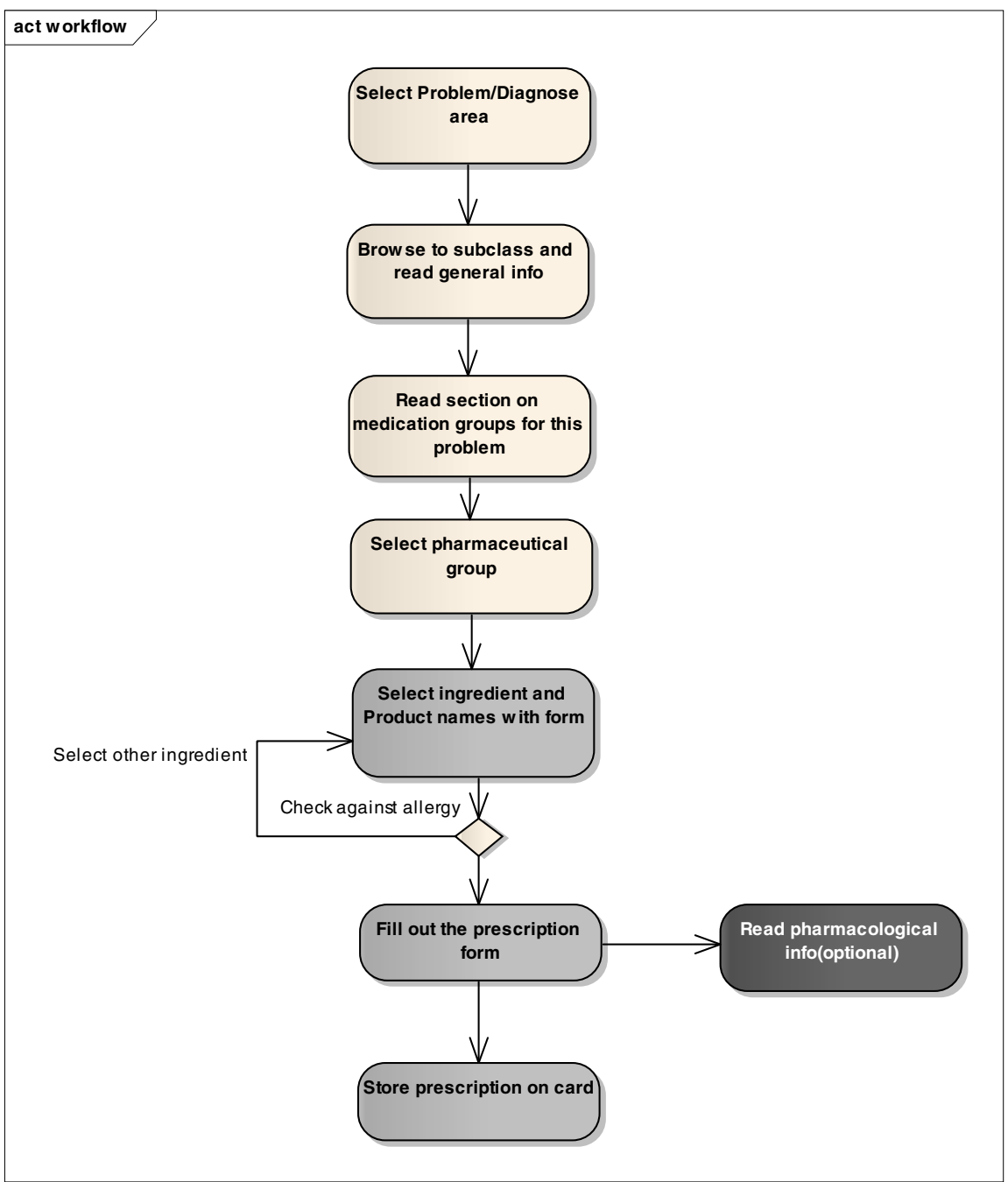

Fig. 1. White activities use the Drug Book, gray activities use the Product database and the dark gray activity uses the Pharmacology database 
The system also used some other important features, which are common today, to complete the prescription form, thus it was possible to calculate the total dosage from the number of portions and intended period of medication. A specific detail of this system was the search for the optimal package (amount of medication and appropriate sizes), to obtain the lowest possible total price.

The control of access to the data on the patient card was based on the interaction between the keys on this card and those on the doctor's card (now generally called Health Professional Cards). The doctor's card used here was a forerunner of the electronic ID card concept and at the time, in 1987, rather unique. Since 1998, the use of smartcards by professionals has been generally accepted and recommended, but despite small trials very few systems still use them, although, for example, fifty thousand cards have been issued in Stockholm [4-6].

The site of the trial for the Patient prescription card was on the island of Tjörn in west Sweden. The County Council and the Pharmacy Corporation participated, of which the latter developed software to read the prescriptions from the cards and integrate them with the software used to process paper prescriptions, the ATS system. Infocard developed all the software for the doctor's office. An approximate three hundred patients and four physicians were included in the pilot study. Although the participants were generally quite positive about the trial, for most of the physicians, this was their first encounter with a PC, and some of the initial problems encountered were related to inexperience in handling a computer with a mouse.

However, the Federation of County Councils hesitated, due to the costs associated with supplying all physicians with computers and all patients with cards, the latter at a cost of approximately 100 SEK per card at the time. Consequently, this initiative, which had the keen support of the Pharmacy Corporation for several years, was never implemented on a large scale.

The focus of the investments in ICT for health care became instead the electronic health records, as reported in another contribution to this conference [7]. These included, in many cases but not all, a module for prescriptions, but for years, these modules were much less advanced than this first Swedish Prescriber Support system and are, in some ways, still not as progressive.

\section{Messaging and Standard Formats}

During the 1990s, when electronic health record systems at the desktop of outpatient clinics increased from 5 percent to 90 percent, there was renewed interest in the electronic transfer of prescriptions using EDI. Denmark was a pioneering country for this method and an Electronic Data Interchange For Administration, Commerce and Transport (EDIFACT) message format was developed on a European scale to represent an electronic prescription. This was adapted to Sweden and used until about 2001 when it was replaced by an XML message format based on the European prestandard ENV 13607. A Danish GP led this development, which had an objectoriented model of the prescription message and some related ones that dealt with an intermediate relaying agent. Initially, they sent all prescriptions directly to one named 
pharmacy; however, it is now possible to send them to a national prescription store from which they are retrieved when patients want them filled.

\section{Public Web Based Knowledge Bases}

The product database has only been available for software producers, but the pharmacological information most widely used in Sweden today is Fass ${ }^{2}$. Fass was available since the mid-1990s without restrictions; it includes a version that uses less technical language and less detail, especially for patients/citizens. Software companies that allow their users to open a window to read from while they are prescribing also use this database. However, there is no link to the different elements of this to allow more informed prescribing. Other national developments offer software companies the opportunity of linking to a database with prescriber information in a different way.

\section{Patient/Citizen Inclusion}

One important aim behind our development of the Prescription system in 1986-88 was to include patients and make them more aware of their complete current medication as prescribed by, unfortunately, often several different care facilities with no connectivity or common database. Therefore, the concept of the patient held data card was important. Our intention was to make this card interoperable internationally as well, at least in Europe. Patient cards based on smartcards were in use much more in certain other countries like France, Germany, and Spain, but prescriptions have only been part of such systems on a relatively small scale.

The patient held data was a practical way of moving the information to all the facilities that patients would need to visit (health care and pharmacies). Very importantly, the system also provided a means of putting the patient in control of the access to the information because only those who received the card could read it. Presuming no one stole it, if such was the case it would probably not have been possible for the thief to read it, the patient decided who to trust to read the medical information the card contained. The data could be quite sensitive, also indirectly informing the reader which diseases were present.

The early system of the 1980s also encouraged doctors to print a table adapted to patient use that listed all the current medication with dosage, to facilitate the correct use. This feature is available in many systems today, but it is, unfortunately, often not adapted well enough to the patients' needs and not used as much as it should be.

Today, despite the advanced general technology with electronic IDs widely used by citizens, only a few places offer patients the service of being able to log onto their record of medication data. A promising approach is the National Patient Overview, which started in 2010 in Örebro County.

\footnotetext{
${ }^{2}$ FASS.SE is published by LINFO, the organization for the pharmaceutical industry, and is not controlled by any authority.
} 
However, the Pharmacy Corporation has offered citizens online access to their new prescriptions in the national prescription store, which any pharmacy could fill, and a printout of all prescription medication they have bought since 2009 . While this is all very well, it does not replace the need for access to current ordination, since dosages do change and some medicines found unsuitable and suspended, despite doctors prescribing them.

\section{Discussion}

The evolution of the use of ICT for improving the use of prescription medication has been far from straightforward. It has included various alternative developments including what now appears to be a parenthesis, the use of patient held smartcards with all prescription information. This is partly due to the rather advanced level of other network-based services including PKI-based security infrastructures. Sweden and Denmark are clearly world leaders with regard to the use of messaging for prescriptions. Nevertheless, even in these two countries, they still use several million paper forms, although most of the sixty million prescriptions in Sweden are now transmitted electronically. This has resulted in a reduction of problems associated with poor handwriting. It is usually a quick and convenient service to patients, since after a phone call to the doctor, a prescription could go directly to any pharmacy and there is no need for the patient to collect a paper form printed by the computer, which is still the main method in most European countries.

However, the most important benefits of ICT support do not relate to the Electronic Transfer, but the associated development of decision support for the prescriber. This support should include a number of different issues, which are only partly available even today.

- A current record of all ordinated medication wherever the patient goes, preferably also internationally

- Access to several types of integrated decision support processes, in addition to books in a web browser

- Integration of the information in the general health record with the pharmaceutical information source to allow, for example, links to diagnosis and the appropriate medications for the illness. In addition, a linkage that automatically creates an alert if a diagnosis or any laboratory tested value creates a reason to avoid prescribing a certain medication or to alter the standard dose

- Support for patients that enables them to manage their medication, including non-prescription items and natural remedies, herbal medicinal products, and traditional herbal medicinal products.

The development of electronic prescribing support in Sweden is an interesting example of different technologies that include the computer on the card. The microprocessor card has become a very important security tool for personnel in Swedish health care, and patient data cards are now in use in many countries, but not in the Nordic ones. The initial standards developed in Europe were adopted as global ISO standards, including a part for prescriptions on cards. 


\section{References}

1. Klein, G.O.: ISO/TR 22790 Health informatics - Functional characteristics of prescriber support systems (2007)

2. Klein, G.O.: Infocard in Pharmacy. In: Proceedings of the North American Conference on Patient Cards, New Orleans, pp. 1-3 (March 1992)

3. Klein, G.O.: The Swedish Prescription Card Trial: A Technical Report. Published by Apoteksbolaget in the co-operation between Sweden and the French Ministry of Health, p. 29 (1992)

4. Klein, G.O.: Final report of the project Trustworthy Health Telematics 1 (Trusthealth). Deliverable D1.4, p. 16 (1998)

5. Klein, G.O.: Security principles for patient card systems. In: Köhler, C.O., Waegeman (eds.) Proceedings of the Fourth Global Congress on Patient Cards and Computerization of Health Records, pp. 77-87. Medical Records Institute, Newton (1992)

6. Klein, G.O.: Smart Cards: A tool for carrying medical information by patients and creating digital signatures by professionals. In: Information Security - The Next Decade Conference of the International Federation of Information processing/TC 11 Security, Annex Information Security on the Electronic highways of Sweden, Cape Town, pp. 1-20. Chapman \& Hall, Boca Raton (1995)

7. Kajbjer, K., Nordberg, R., Klein, G.O.: Electronic Health Records in Sweden: From Administrative Support to Clinical Decision Support. In: Lundin, P., Impagliazzo, J., Wangler, B. (eds.) HiNC3. IFIP AICT, vol. 350, pp. 65-73. Springer, Heidelberg (2011) 